\title{
Stochastic Mortality, Macroeconomic Risks and Life Insurer Solvency
}

\author{
Katja Hanewald ${ }^{\mathrm{a}}$, Thomas Post ${ }^{\mathrm{b}}$ and Helmut Gründl ${ }^{\mathrm{c}}$ \\ ${ }^{a}$ Australian School of Business, School of Actuarial Studies, University of New South Wales, \\ Sydney NSW 2052, Australia. \\ E-mail: k.hanewald@unsw.edu.au \\ ${ }^{\mathrm{b}}$ School of Business and Economics, Department of Finance, Maastricht University, Tongersestraat 53, \\ 6211 LM Maastricht, The Netherlands. \\ E-mail: t.post@maastrichtuniversity.nl \\ ${ }^{c}$ Faculty of Economics and Business Administration, Chair of Insurance and Regulation, International \\ Center for Insurance Regulation, Goethe-Universität Frankfurt am Main, Grüneburgplatz 1, \\ 60323 Frankfurt am Main, Germany. \\ E-mail: gruendl@finance.uni-frankfurt.de
}

Motivated by a recent demographic study establishing a link between macroeconomic fluctuations and the mortality index $k_{t}$ in the Lee-Carter model, we develop a dynamic asset-liability model to assess the impact of macroeconomic fluctuations on the solvency of a life insurance company. Liabilities in this stochastic simulation framework are driven by a GDP-linked variant of the Lee-Carter mortality model. Furthermore, interest rates and stock prices react to changes in GDP, which itself is modelled as a stochastic process. Our simulation results show that insolvency probabilities are significantly higher when the reaction of mortality rates to changes in GDP is incorporated.

The Geneva Papers (2011) 36, 458-475. doi:10.1057/gpp.2011.14; published online 15 June 2011

Keywords: life insurance; asset liability management; stochastic mortality; Lee-Carter model; business cycle

\section{Introduction}

Assumptions about future mortality rates are an integral part of the pricing, reserving, and risk management of insurance companies or pension funds offering annuity and life insurance contracts. Systematic deviations of actual mortality rates from these assumptions can pose a serious threat to the financial stability of those businesses and to the economic well-being of policy-holders. Thus, there has been considerable recent research into developing models that allow for stochastic mortality, that is, models that allow for systematic deviations from mortality trends.

In another stream of demographic research, several epidemiological studies find that mortality rates react to changes in macroeconomic conditions. By combining results from both fields of study, a recent contribution shows that the mortality index $k_{t}$ in the well-known Lee-Carter model is significantly correlated with macroeconomic changes. ${ }^{1}$ This insight is the inspiration for the present study, which

\footnotetext{
${ }^{1}$ Hanewald (2011).
} 
develops a dynamic asset-liability model for the assessment of the overall impact of macroeconomic fluctuations on the financial stability of a life insurance company. In this model, both assets and liabilities are allowed to react to the state of the economy. Exemplary simulation results for realistically chosen model parameters show that insolvency probabilities are considerably higher when the reaction of mortality rates to changes in the economic indicators is incorporated compared to scenarios where this relationship is ignored. This finding is robust to variations in the age of the insureds, the insurance portfolio size, the equity base and the share of assets invested in stocks.

The paper is organised as follows. Section "Related literature" contains a review of relevant literature. This is followed, in Section "The simulation framework", by setting up the simulation model for the insurance company. Results of different simulation scenarios are presented in Section "Simulation results". A summary and conclusions are provided in Section "Conclusion and outlook".

\section{Related literature}

The field of mortality modelling has undergone substantial development in the past few years. ${ }^{2}$ The earliest and still the most popular model was proposed by Lee and Carter. ${ }^{3}$ This model is widely employed both in the academic literature and by practitioners working for pension funds, life insurance companies and public pension systems. The original approach has seen several extensions, ${ }^{4}$ and has been applied to mortality data of many countries, including the G-7 countries, Australia, Belgium, China and South Korea, and Spain. ${ }^{5}$ For mortality modelling, the Lee-Miller variant is generally viewed as the standard. ${ }^{6}$ It performs well in a ten-population comparison study of five variants or in extensions of the Lee-Carter method. ${ }^{7}$

The key driver of mortality dynamics in the Lee-Carter model is the index of the level of mortality $k_{t}{ }^{8}$ This variable is typically characterised as the dominant temporal pattern in the decline of mortality, a random period effect, or simply as a latent variable. ${ }^{9}$ However, a recent study using data for six OECD countries (Australia, Canada, Japan, the Netherlands, the United Kingdom and the United States) reveals that the mortality index in the Lee-Carter model is not merely an unobserved, latent variable that fluctuates erratically. ${ }^{1}$ The study reports significant correlations between changes in $k_{t}$ and real gross domestic product (GDP) growth rates or unemployment rate changes for all six countries studied over the period 1950-2006.

\footnotetext{
${ }^{2}$ For overviews see Cairns et al. (2008), Booth (2006) or Booth and Tickle (2008).

${ }^{3}$ See Cairns et al. (2008).

${ }^{4}$ See, for example, Lee and Miller (2001), Brouhns et al. (2002) or Renshaw and Haberman, 2006).

${ }^{5}$ See Tuljapurkar et al. (2000) for the G-7 countries, Booth et al. (2002) for Australia, Denuit (2009) for Belgium, Li et al. (2004) for China and South Korea, and Debón et al. (2008) for Spain.

${ }^{6}$ Booth and Tickle (2008).

${ }^{7}$ Booth et al. (2006).

${ }^{8}$ Lee and Carter (1992).

${ }^{9}$ Tuljapurkar et al. (2000): "Dominant temporal pattern in the decline of mortality"; Cairns et al. (2008): "A random period effect"; Hári et al. (2008a): "Latent variable".
} 
The results of cointegration analyses provided in the study confirm that these correlations result from a long run causal relationship between mortality and macroeconomic fluctuations. However, further analysis of the mortality rates from six main causes of death shows that most cause-specific mortality rates show pronounced trends over the past decades. These trends change the composition of deaths and alter how total mortality reacts to external factors such as macroeconomic fluctuations. A comparison of the two subperiods 1950-1979 and 1980-2006 then shows that the link between the economy and total mortality is subject to a major change that even results in a reversal from procyclical to countercyclical in the latter subperiod.

Hanewald's findings for the period 1950-2006 are in line with results of several previous studies that relate (age-specific) mortality rates directly to macroeconomic conditions. Ruhm was the first to discover that total mortality, as well as several cause-specific mortality rates (e.g., motor vehicle fatalities, deaths from cardiovascular disease, liver ailments or flu/pneumonia), fluctuated procyclically in the United States over the period $1972-1991 .{ }^{10}$ Similar procyclical patterns were observed for mortality rates in France, Germany, Japan, Spain, Sweden and for 23 OECD countries over the period $1960-1997 .{ }^{11}$

There is evidence for the structural change in the link between mortality and the economy, as well. For Japan, a structural break in the effect of macroeconomic fluctuations on total mortality occured at ages $20-44$ and 45-64 years in $1978 .{ }^{12}$ An explanation is found in changes in the composition of causes of death which alter the reaction of aggregate mortality to economic conditions. In most industrialised countries, an increase is observed in both deaths attributable to (countercyclical) diabetes and hypertensive disease ${ }^{12}$ and in (acyclical/countercyclical) cancer deaths. ${ }^{13}$ Apart from that there was a dramatic decline in (procyclical) cardiovascular diseases mortality at the beginning of the 1970s. ${ }^{14}$ Furthermore, reductions in (procyclical) motor vehicle fatalities are reported for a large number of OECD countries. ${ }^{15}$

The financial impact of systematic mortality risk on a life insurer or pension fund is analysed in several models. A large number of studies tries to quantify the impact of stochastic mortality on insurers' risk exposure, many of them focusing on systematic mortality improvements ("longevity risk"). ${ }^{16}$ Other studies analyse strategies to manage systematic mortality risk such as natural hedging opportunities between annuity and life insurance business, optimal asset allocation strategies or the design of

\footnotetext{
${ }^{10}$ Ruhm (2000). Similar results for the United States are reported by Tapia Granados (2005a) and Reichmuth and Sarferaz (2008).

${ }^{11}$ See Reichmuth and Sarferaz (2008) for France, Neumayer (2004) and Hanewald (2010) for Germany, Reichmuth and Sarferaz (2008) and Tapia Granados (2008) for Japan, Tapia Granados (2005b) for Spain, Tapia Granados and Ionides (2008) for Sweden, and Gerdtham and Ruhm (2006) for the 23 OECD countries.

12 Tapia Granados (2008).

${ }^{13}$ See Ruhm (2000) and Tapia Granados (2008).

${ }^{14}$ See Levy (1981) and Uemura and Pisa (1988).

${ }^{15}$ Page (2001).

${ }^{16}$ See, for example, Dowd et al. (2006), Hári et al. (2008b), Bauer and Weber (2008) or Mao et al. (2008).
} 
new insurance products. ${ }^{17}$ None of the studies, however, accounts for the systematic dependency of mortality rates on the economic environment as proxied by real GDP, which is the contribution of this paper.

\section{The simulation framework}

\section{The model for the insurance business}

Our aim is to assess the overall impact of macroeconomic fluctuations on a life insurer's solvency. We set up a dynamic asset liability model of a life insurance company as described below.

Consider a newly founded life insurance company. At the beginning of its first year, in $t=0$, it writes $I_{0}$ homogeneous term-life contracts ${ }^{18}$ with annually constant premium $P$ per contract. All insureds are assumed to be of age $x$. The contract duration is for $T$ years and the death benefit is $B$. For each contract, the premium $P$ is collected immediately. Shareholders contribute a fixed proportion $\gamma$ of the premium income $I_{0}$. $P$ as equity capital $E_{0}$. The sum of premiums and equity comprises the insurer's assets $A_{0}$.

We assess the insurer's financial stability by its insolvency probability. Insolvency occurs when the firm's equity - measured at market value - is negative at the end of the year. Insolvent insurance firms are not allowed to continue operating. The target variable of our analysis is the multi-period insolvency probability $\psi_{t}$ of the insurance firm, which is defined by the probability that, at the end of year $t$, one of the following conditions is true: for an insurer being solvent at year $t-1$ the insurer's equity capital is negative in year $t$, or the insurer was already insolvent in the previous year. This measure provides a potential insurance buyer (or regulator) with an important metric to evaluate a contract's financial quality: For various planning horizons $t$, it directly gives the probability that the insurer will still exist at that future period and will be able to pay out insurance benefits in case the policy-holder were to die.

Equity capital at time $t$ is the difference between the market value of assets $A_{t}$ and the liabilities $L_{t}$ at the end of the year:

$$
E_{t}=A_{t}-L_{t}
$$

Asset values are given by:

$$
A_{t}=\left(A_{t-1}+P \cdot I_{t-1}\right) \cdot R_{t}-B \cdot\left(\Delta I_{t}\right)-D_{t},
$$

${ }^{17}$ See Gründl et al. (2006), Cox and Lin (2007), Tsai et al. (2010), and Wang et al. (2010) for a natural hedging opportunity, Yang and Huang (2009) for asset allocation strategies of defined contribution pension plans and Ferro (2009) for the design of new insurance products.

${ }^{18}$ Ruhm (2000) and Tapia Granados (2008) show that the reaction of mortality rates to real GDP is stronger for the working-age population than for retirees. Therefore, we look at term-life contracts and not, for example, at annuities. 
where $R_{t}$ is the stochastic investment return (i.e., $\exp \left(\right.$ rate of return)), $B \cdot\left(-\Delta I_{t}\right)$ are the claims payments, $\Delta$ is the lag operator and $D_{t}$ is the annual dividend paid out to shareholders.

With $\mathrm{PV}_{t}[\cdot]$ denoting a present value operator, which is specified in Section "Random variables and stochastic processes", the market value of year-end liabilities $L_{t}$ is given by:

$$
\begin{aligned}
L_{t}= & \mathrm{PV}_{t}[\text { Future claims payment }] \\
& -\mathrm{PV}_{t}[\text { Future premium income }] .
\end{aligned}
$$

Dividends $D_{t}$ at the end of the year are a constant fraction $d$ of the insurer's net income for that year $N_{t}$ when $N_{t}$ is positive; zero otherwise. Formally, $D_{t}$ is given by:

$$
D_{t}=\max \left\{d \cdot N_{t}, 0\right\}
$$

where net income $N_{t}$ is defined as:

$$
N_{t}=A_{t-1} \cdot\left(R_{t}-1\right)+P \cdot I_{t-1} \cdot R_{t}-B \cdot\left(-\Delta I_{t}\right)-\Delta L_{t}
$$

\section{Random variables and stochastic processes}

We now define the stochastic processes driving our model. Real GDP is introduced first; it is the fundamental link between the other random variables, that is, the number of surviving insureds $I_{t}$ (driven by the mortality index $k_{t}$ ) and capital market returns $R_{t}$.

Following previous work, a lognormal distribution is assumed for real GDP. ${ }^{19}$ Thus annual changes in log real GDP are given by:

$$
\Delta \ln \left(\operatorname{real} G D P_{t}\right)=\mu_{G D P}+\sigma_{G D P} \cdot \varepsilon_{G D P, t},
$$

where $\mu_{G D P}$ and $\sigma_{G D P}$ denote the mean and standard deviation of real GDP growth rates and $\varepsilon_{G D P, t}$ is a standardised normal random variable.

The number of deaths at the end of each year $-\Delta I_{t}$ follows a binomial distribution $\mathrm{B}\left(I_{t-1}, q_{x+t-1, t}\right)$. We hereby account for unsystematic mortality risk, that is, the fact that the actual number of deaths might deviate from the expected number. The probability for each insured aged $x+t-1$ at the beginning of a year to die at the end of the year $t$ is denoted as $q_{x+t-1, t}$. Considering stochastic mortality, that is, accounting for systematic mortality risk, the probability $q_{x+t-1, t}$ itself is also a random variable realising in $t$. Age-specific mortality probabilities $q_{x, t}$ are derived from the central

\footnotetext{
${ }^{19}$ Kruse et al. (2005).
} 
death rates $m_{x, t}$ of a Lee-Carter-type model, using the approximation: ${ }^{20}$

$$
\frac{q_{x, t}=m_{x, t}}{\left(1+0.5 \cdot m_{x, t}\right)}
$$

According to the Lee-Carter approach, and abstracting from age-specific shocks, ${ }^{21}$ central death rates $m_{x, t}$ are given by:

$$
m_{x, t}=\exp \left(a_{x}+b_{x} \cdot k_{t}\right),
$$

where $a_{x}$ is an age-specific constant and $b_{x}$ describes the sensitivity of age-specific mortality rates to changes in the mortality index $k_{t}$, which is a random variable.

As in the original Lee and Carter model, the stochastic process for the mortality index $k_{t}$ is modelled as a random walk with drift:

$$
\Delta k_{t}=\theta+\sigma_{k} \cdot \varepsilon_{k, t},
$$

with $\varepsilon_{k, t}$ being a standardised normal random variable.

In summary, there are two sources of randomness in our model for the number of deaths. One is based in the uncertainty regarding the path of the underlying mortality index $k_{t}$. The other source of randomness results from sampling the insurance portfolio.

Distribution of the asset return $R_{t}$ depends on the insurer's asset allocation decisions. Following Kling et al., ${ }^{22}$ we allow for two lognormally distributed investment opportunities: stocks and bonds. Let $r_{s, t}$ denote the stock log-return in period $t$ and $r_{b, t}$ the bond log-return, and let $\alpha \in[0,1]$ be the fraction of assets invested in stocks. Then, the return of the annually rebalanced asset portfolio $R_{t}$ is given by:

$$
R_{t}=\alpha \cdot \exp \left(r_{s, t}\right)+(1-\alpha) \exp \left(r_{b, t}\right)
$$

where

$$
\begin{gathered}
r_{s, t}=\mu_{s}+\sigma_{s} \cdot \varepsilon_{s, t}, \text { and } \\
r_{b, t}=\mu_{b}+\sigma_{b} \cdot \varepsilon_{b, t},
\end{gathered}
$$

with $\mu_{s}, \mu_{b}, \sigma_{s}$ and $\sigma_{b}$ denoting the mean and standard deviation of log-returns, and $\varepsilon_{s, t}$ and $\varepsilon_{b, t}$ being standardised normal random variables.

${ }^{20}$ Cairns et al. (2008).

${ }^{21}$ It is common in the literature to ignore the age-specific error term $\varepsilon_{x, t}$ at this stage of the model (see, e.g., Cairns et al., 2008). A justification is provided by Lee and Carter (1992) themselves, who show that up to 90 per cent of the standard errors of age-specific death rate forecasts are accounted for by uncertainty in $k_{t}$ (Lee and Carter, 1992, Table.B2, forecast horizon of ten years).

${ }^{22}$ Kling et al. (2007). 
In a last step, we specify the value of the insurer's liabilities at the end of each year $L_{t}$, which were introduced in Eq. (3). At the end of every year, the insurer observes the realised bond returns and the current level of the mortality index $k_{t}$. The insurer uses the latter as a starting point for projecting future mortality rates; observed bond returns are used to discount expected liabilities. Thus, the market value of liabilitiesin the instant between that year's claim payments and next year's premium income-is given by:

$$
L_{t}=I_{t} \cdot E_{t}\left[B \cdot \sum_{\tau=t+1}^{T} \frac{{ }^{\tau-t} q_{x+t, t}}{e^{r_{b, t} \cdot(\tau-t)}}-P \cdot \sum_{\tau=t}^{T-1} \frac{\tau-t}{e^{r_{b, t}}(\tau-t)}\right]
$$

where ${ }_{i} q_{x, t}$ is the probability that an insured aged $x$ will die after age $x+i-1$, while ${ }_{i} p_{x, t}$ is the probability that an insured aged $x$ will survive at least another $i$ years. The insurer calculates both probabilities conditional on the information available at time $t$. In Eq. (12), the present value calculus is specified by taking the expectation of future cash flows with respect to the real-world probability measure without further risk adjustments. Thus, we assume that the insurer is unaware of any correlations between mortality and GDP or the capital market development, that is, the insurer does not consider the systematic nature of mortality risk.

In summary, economic and demographic randomness in our model are induced by the following random variables: the mortality index $k_{t}$, real GDP growth rates and bond and stock returns. The main contribution of this paper is to account for the interaction of these factors, especially the dependency between mortality rates and economic conditions, which we accomplish by allowing for a correlation matrix with nonzero off-diagonal elements for the random variables $\varepsilon_{k, t}, \varepsilon_{s, t}, \varepsilon_{b, t}$ and $\varepsilon_{G D P, t}{ }^{23}$

\section{Numerical calibration of the model}

Calibration of the model involves estimating parameters of the stochastic processes from empirical data, as well as setting insurance contract and management parameters. We begin with a base scenario, but will vary several of the parameters later on in the analysis.

\section{Management assumptions}

The fixed proportion $\gamma$ of the first premium income $I_{0} \cdot P$ raised as initial equity capital $E_{0}$ is set to 0.1 . The dividend ratio $d$, that is, the constant fraction of the insurer's net income paid out to shareholders, is set to 0.1 . The asset fraction $\alpha$ that is invested in stocks is set to 0.3 . This parameter set results in reasonably small one-period insolvency probabilities.

${ }^{23}$ Demographic studies show that the impact of changes in the macroeconomic conditions on mortality rates is primarily contemporary (see, e.g., Tapia Granados, 2005a,b). Our data confirm this finding. Correlation between the mortality index and GDP growth rates of the previous year turned out to be close to zero. Therefore, we only account for correlations at time $t$ in our model. 


\section{Contract characteristics}

We consider a term-life insurance contract with a duration of $T=10$ years and a death benefit of $B=\$ 100,000$. This contract is sold to $I_{0}=10,000$ insureds in $t=0$. In the base scenario, all insureds are male and of age $x=40$. Mortality data is available up until 2005; therefore, the simulation starts with $t=0$ at the beginning of 2006.

The fair premium for an individual contract is calculated by solving Eq. (13) for $P_{\text {fair }}$ :

$$
E_{0}\left[P_{\text {fair }} \cdot \sum_{\tau=0}^{T-1} \frac{{ } p_{x, 0}}{e^{r_{b, 0} \tau}}\right]=E_{0}\left[B \cdot \sum_{\tau=1}^{T} \frac{\tau}{{ } q_{x, 0}} e^{r_{b, 0}}\right]
$$

Thus, the same assumptions used to calculate future liabilities in Eq. (12) apply for premium calculation. The contract is sold at a premium $P$ that includes a proportional loading $\lambda$ on the fair premium, which, in the base scenario, is set to 0.1 :

$$
P=(1+\lambda) \cdot P_{\text {fair }}
$$

\section{Stochastic processes}

Death rates and population size for the United States were obtained from the Human Mortality Database. ${ }^{24}$ A series for real GDP was obtained from the website of the U.S. Bureau of Economic Analysis. ${ }^{25}$ For calibration of the return processes we use annual total returns of large company stocks and U.S. treasury bills. ${ }^{26}$ In the following, these series are referred to as real GDP, stock returns and bond returns.

The Lee-Carter model was estimated with the $\mathrm{R}$ package demography. ${ }^{27}$ The LeeMiller variant was chosen ${ }^{28}$; it has been widely adopted as the standard Lee-Carter method $^{6}$ and involves estimating the model for the latter half of the twentieth century. ${ }^{29}$ Male and female forecasts are treated as two separate applications of the basic Lee-Carter approach. ${ }^{30}$ The model is estimated with the same upper age limit as in the original (85 years) article by Lee and Carter and a minimum age of 30 years. Figure 1 plots the estimated parameters $a_{x}$ and $b_{x}$ that are needed to derive age-specific death rates $m_{x, t}$ from the mortality index $k_{t}$. Figure 2 plots the mortality index $k_{t}$ that was extracted for U.S. males for 1950-2005, together with the 2006-2015 forecast.

\footnotetext{
${ }^{24}$ University of California and Max Planck Institute (2008).

${ }^{25}$ Bureau of Economic Analysis (2008). The corresponding time series is called "GDP in billions of chained 2,000 dollars". "Chained dollars" refers to a method for calculating a price index that is used to adjust nominal GDP values for inflation.

${ }^{26}$ Morningstar (2008).

${ }^{27}$ Hyndman et al. (2008).

${ }^{28}$ Lee and Miller (2001).

${ }^{29}$ Furthermore, the approach involves adjustment of the mortality index $k_{t}$ to life expectancy $e_{0}$ instead of total deaths, and forecasting forward from observed (rather than fitted) rates.

${ }^{30}$ Lee (2000).
} 


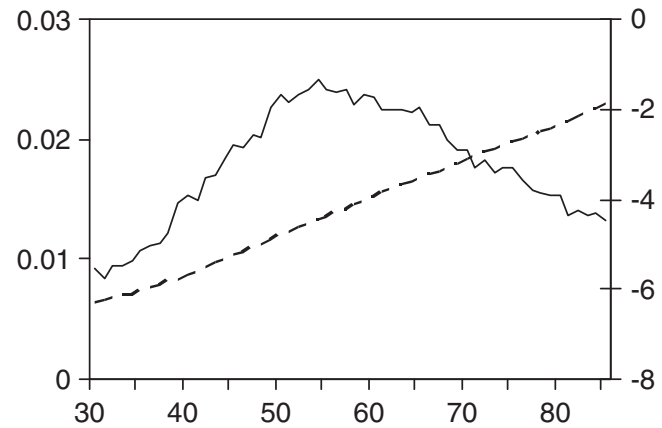

Figure 1. Fitted values for $a_{x}$ (dashed, right axis) and $b_{x}$ (solid, left axis) for ages 30-85.

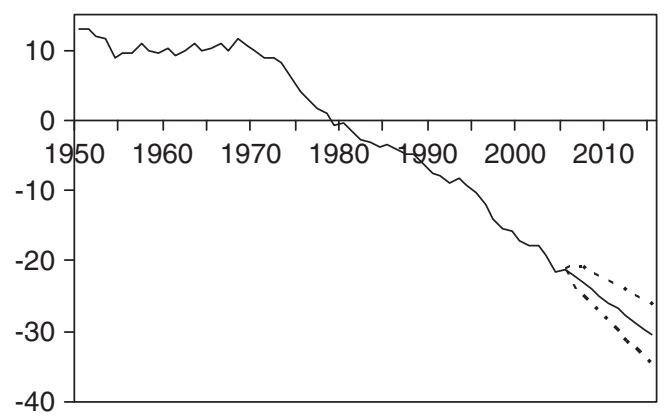

Figure 2. Mortality index $k_{t}$, fitted values 1950-2005, forecast 2006-2015 with 95 per cent confidence band.

The extracted time series for the mortality index $k_{t}$, together with the time series for GDP and returns, are used to estimate the parameters and correlation structure of the four exogenous stochastic processes. Based on results from Hanewald that document a structural change in the correlation structure between real GDP growth rates and the mortality index in six OECD countries over the period 1950-2005, we decide to use a shorter period for estimating the parameters. Using a bivariate regression where changes in the estimated mortality index $k_{t}$ are regressed on the real GDP growth rates we identify a significant break point for 1989 with the Chow breakpoint $\operatorname{test}^{31}$ and therefore use the period 1989-2005 for parameter estimation.

Table 1 summarises the estimated parameters and correlation structure.

\section{Simulation results}

Assuming the exemplary set of model parameters described above, the insurance company model was simulated with 100,000 iterations using the Latin Hypercube

\footnotetext{
${ }^{31}$ Chow (1960).
} 
Table 1 Estimation results, 1989-2005

\begin{tabular}{|c|c|c|c|c|}
\hline & $\begin{array}{l}\text { Real GDP } \\
\text { growth rates }\end{array}$ & $\begin{array}{l}\text { Stock } \\
\text { returns }\end{array}$ & $\begin{array}{l}\text { Bond } \\
\text { returns }\end{array}$ & $\begin{array}{l}\text { Changes in the } \\
\text { mortality index }\end{array}$ \\
\hline & $\Delta \ln \left(\right.$ real $\left.G D P_{t}\right)$ & $r_{s, t}$ & $r_{b, t}$ & $\Delta k_{t}$ \\
\hline Mean & 0.029 & 0.110 & 0.043 & -0.955 \\
\hline Standard Deviation & 0.013 & 0.167 & 0.020 & 0.828 \\
\hline \multicolumn{5}{|l|}{ Correlation matrix } \\
\hline Real GDP & 1.000 & 0.282 & 0.050 & -0.395 \\
\hline Stock returns & & 1.000 & 0.266 & -0.286 \\
\hline Bond returns & & & 1.000 & -0.195 \\
\hline Mortality index & & & & 1.000 \\
\hline
\end{tabular}

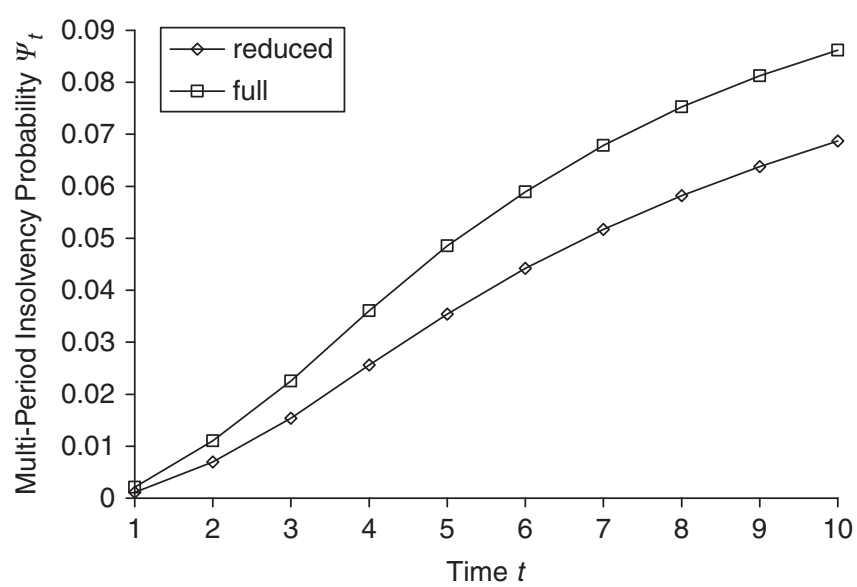

Figure 3. Multi-period insolvency probability $\psi_{t}$, base parameter calibration, full correlation structure vs. reduced correlation structure.

technique. ${ }^{32}$ As a benchmark for comparison, we first simulate a version of the model that ignores the impact of macroeconomic changes on mortality rates. This scenario assumes that the mortality index $k_{t}$ in the Lee-Carter model is uncorrelated with economic conditions as reflected by the processes for GDP, stocks and bonds, that is, entries in the last column of the correlation matrix in Table 1 are set to zero (except the last value, which is one). Next, the scenario employing the full correlation structure is simulated. The difference in insolvency probabilities between the two scenarios is a measure of model misspecification risk. Results are given in Figure 3.

Multi-period insolvency probabilities increase over time in both scenarios. There are two reasons for this: first, confidence intervals for the realisations of the random ${ }^{32}$ McKay et al. (1979). The Latin Hypercube technique yields fast convergence, thus all differences between
insolvency probabilities derived are significant at the 1 per cent level-based on the $z$-test for proportions. 
variables, for example, for the mortality index $k_{t}$ (c.p., Figure 2), broaden with an increasing time horizon; and second, insolvency probabilities cumulate because firms that become insolvent remain insolvent.

Looking at Figure 3 reveals that employing the full correlation structure increases the insolvency probability for every time horizon considered. Thus, ignoring the correlations between the mortality index $k_{t}$ and the economic variables will result in a systematic underestimation of the true insolvency probability. This will occur because the true correlation structure links assets and liabilities in a very unfavourable way: a drop in GDP, in tendency, coincides with lower stock and bond returns, that is, with a shrinking asset base, along with a higher mortality index $k_{t}$, resulting in higher liabilities. Both effects take a toll on equity capital. In absolute numbers, the difference in insolvency probabilities between the two scenarios increases from 0.1 percentage points in $t=1$ to 1.8 percentage points in $t=10$.

Figure 4 plots multi-period insolvency probabilities for four different initial ages $x$ of insureds.

For all four ages, we again observe higher insolvency probabilities under the full correlation structure, meaning that our results are robust to changes in age. However, there are two noteworthy effects that result from varying the age parameter. First,
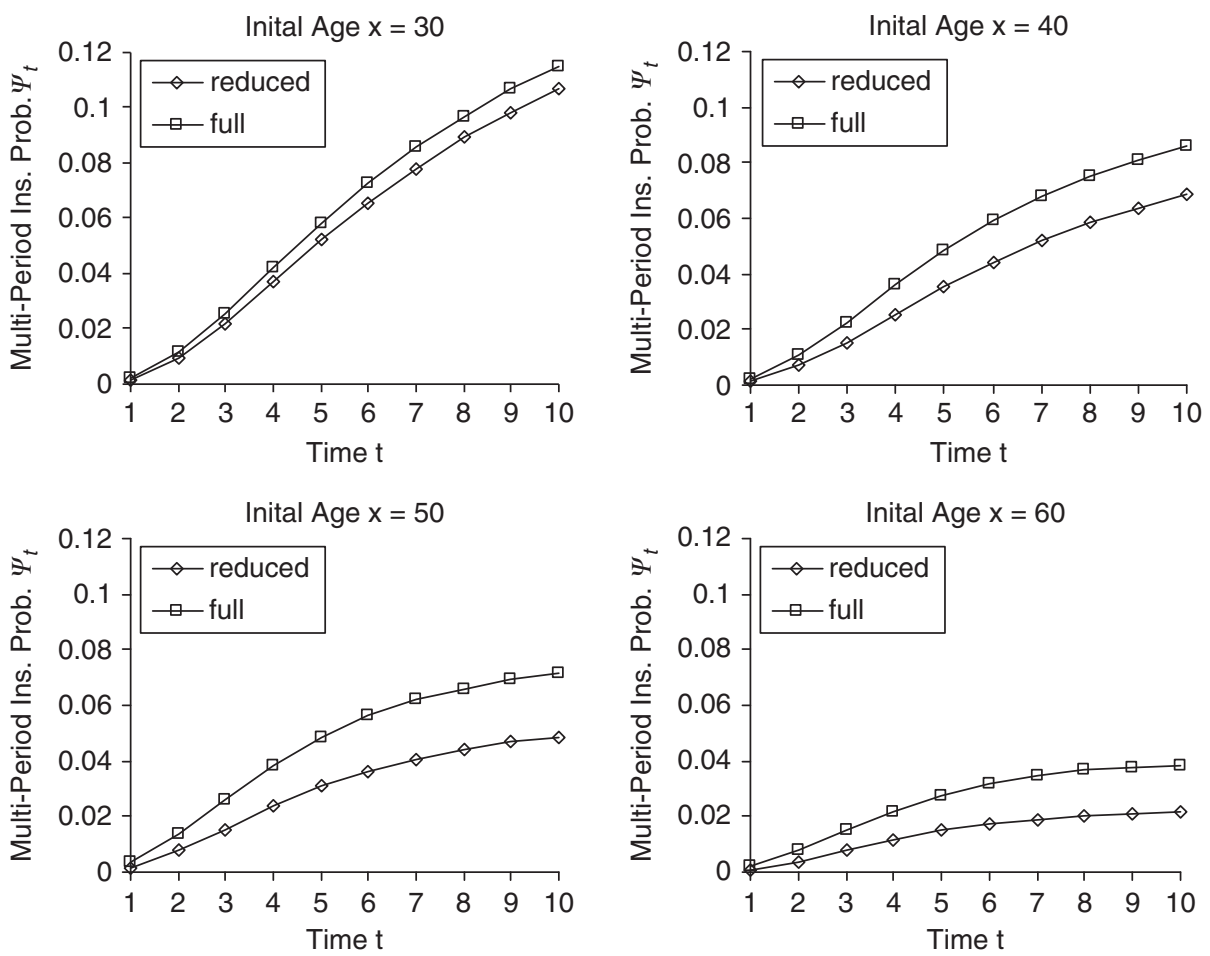

Figure 4. Multi-period insolvency probabilities $\psi_{t}$, reduced and full correlations structure, different initial ages $x$. 
insolvency probabilities decrease in initial age. This is due to the fact, that for higher ages generally the variation of the number of deaths around the (now higher) mean in relative terms, that is, the variation coefficient is smaller. Second, the increase in insolvency probabilities from switching to the full correlation scenario is greater at higher ages $x$, except for age $x=60$. This effect is explained by the different sensitivity of the age-specific death rates to shocks in the mortality index $k_{t}$, which is controlled by $b_{x}$ (c.p., Eq. (8)). As can be seen in Figure 1, the parameter $b_{x}$ exhibits a humpshaped profile, peaking around age 50 years. For that reason, we observe a smaller absolute increase in insolvency probability for age $x=60$ years in comparison to age $x=50$ years.

The effect of different initial insurance portfolio sizes $I_{0}$ is illustrated in Figure 5.

Not surprisingly, we find that insolvency probabilities are generally higher for smaller portfolios due to a less pronounced risk pooling. However, in relative terms, ignoring the true correlation structure leads to a more severe underestimation of the true insolvency probability for larger portfolios. For example, the relative change in the level of the ten-year insolvency probability amounts to +10.5 per cent for $I_{0}=5,000$ insureds vs. +53.1 per cent for $I_{0}=20,000$ insureds. This effect can be explained by noting that in small portfolios less unsystematic risk is eliminated compared to large portfolios. By accounting for the full correlation structure, a similar amount of systematic risk (in absolute terms) is added to the risk exposure of both small and large portfolios, leading to a higher relative increase in the overall risk, measured by the insolvency probability, for large portfolios. In other words, for both small and large portfolios the diversification potential decreases, but with more severe consequences for a portfolio originally believed to be well-diversified.

Figure 6 plots multi-period insolvency probabilities for three different fractions $\gamma$ used when calculating initial equity $E_{0}$.

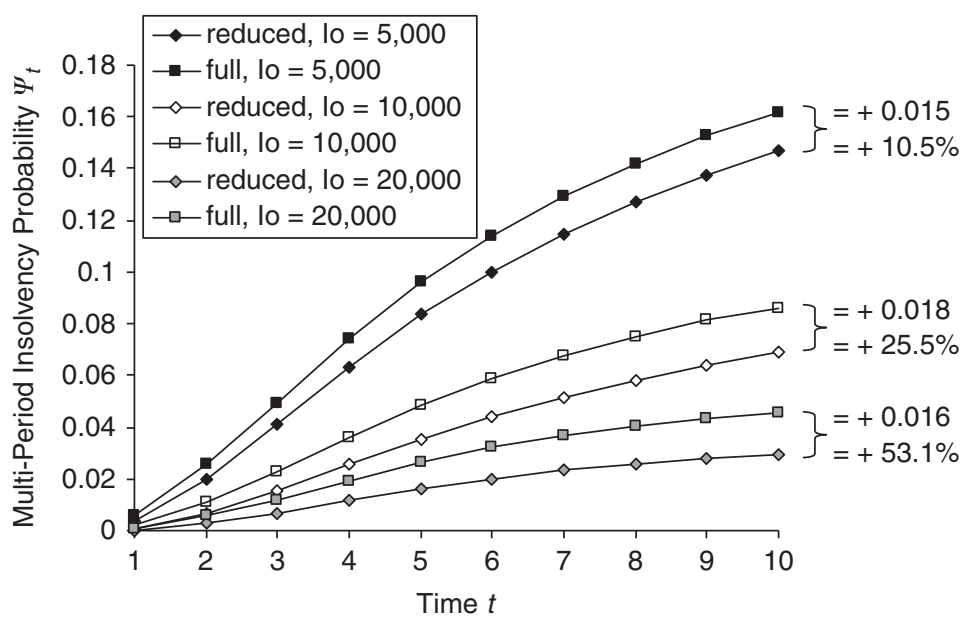

Figure 5. Multi-period insolvency probabilities $\psi_{t}$, reduced and full correlations structure, different initial numbers of insureds $I_{0}$. 


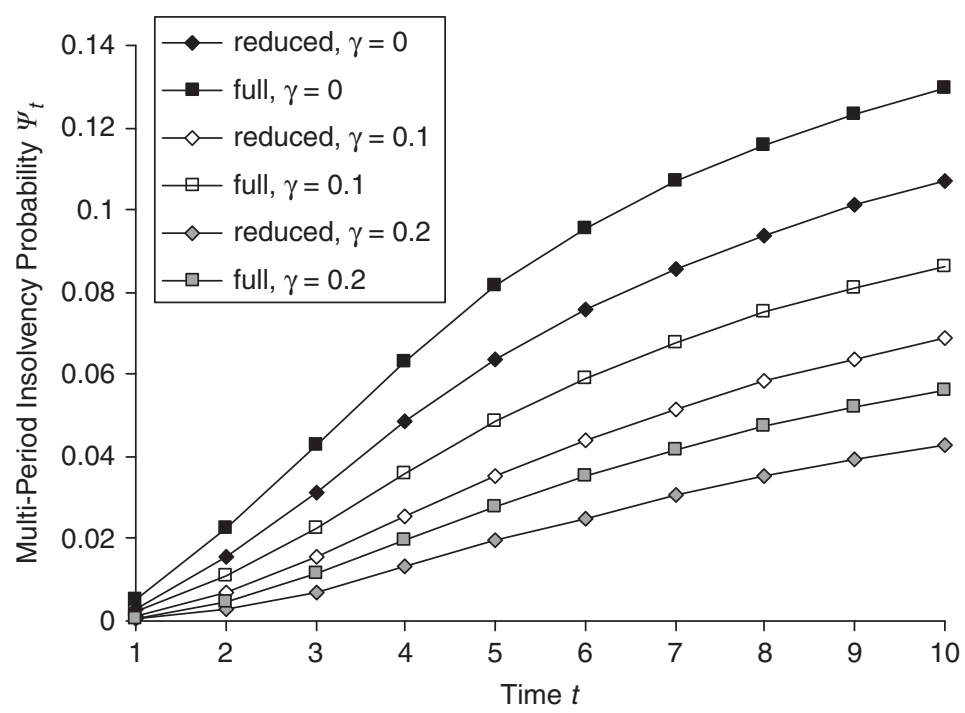

Figure 6. Multi-period insolvency probability $\psi_{t}$, reduced and full correlations structure, different equity buffer factors $\gamma$.

Insolvency probabilities in Figure 6 are similar, and for similar reasons, to those shown in Figure 5. A higher equity buffer, that is, a higher constant fraction $\gamma$ of initial premium income raised as equity capital, improves the insurer's solvency situation. Adding, through implementing the full correlation structure, a similar absolute amount of systematic risk on top of the three considered risk exposures leads to a larger relative increase in risk for higher initial amounts of equity capital. In this sense, safer firms, meaning those with greater equity capital, suffer more from the described model risk.

Multi-period insolvency probabilities for different fractions $\alpha$ of assets invested in stocks are plotted in Figure 7.

First, Figure 7 again confirms that insolvency probabilities are always higher under the full correlation structure.

Second, we observe some general effects of increasing the proportion of stocks in the asset portfolio. On the one hand, the higher expected return of stocks can lead to reduced insolvency probabilities as assets accumulate more rapidly (compare $\alpha=0$ with $\alpha=0.1$, and $\alpha=0.3$ with $\alpha=0.5$ ). On the other hand, the higher volatility of stocks can worsen the insurer's solvency situation (compare $\alpha=0.1$ with $\alpha=0.3$ ).

Third, the proportion of stocks influences the difference in insolvency probabilities between the two scenarios, both in absolute and in relative terms. A larger fraction of stocks induces a higher exposure of the insurer to the unfavourable dependency between GDP, assets and mortality, thus liabilities, that was described under Figure 1. Hence, ignoring the full correlation structure results in a more severe underestimation of insolvency probability by insurers heavily invested in stocks. 

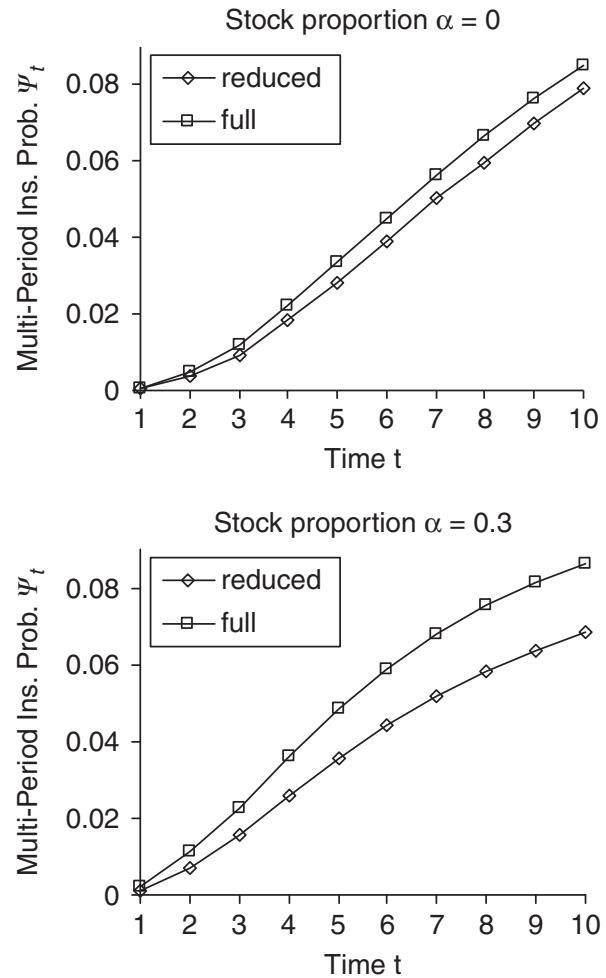
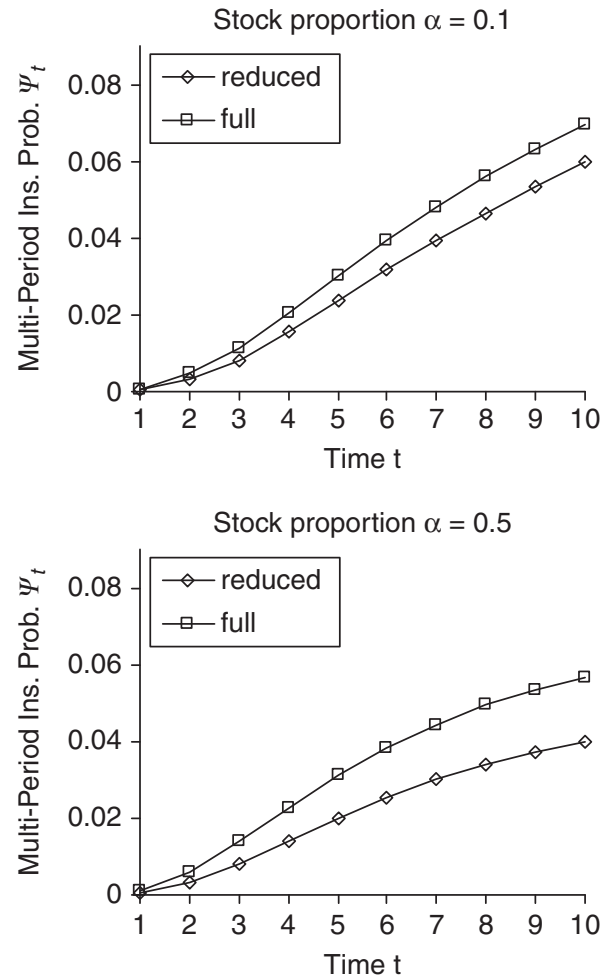

Figure 7. Multi-period insolvency probabilities $\psi_{t}$, reduced and full correlations structure, different proportions $\alpha$ of assets invested in stocks.

\section{Conclusion and outlook}

Based on demographic findings establishing a link between macroeconomic conditions and mortality, we develop a dynamic asset liability model to assess the impact of macroeconomic fluctuations on the financial stability of a life insurance company. This model allows both assets and liabilities to react to the state of the economy. Stochastic drivers in our model are real GDP, mortality, bond returns and stock returns.

Our simulation results for realistically calibrated model parameters show that multiperiod insolvency probabilities are considerably higher when taking into account the dependencies between the mortality index $k_{t}$ in the Lee-Carter model and economic conditions. Thus, ignoring the existing dependency structure will lead an insurer to systematically underestimate its true insolvency probability. This result is robust to variations in the age of insureds, portfolio size, equity base and asset allocation. Through the systematic nature of mortality risk, the relative increase in insolvency probability is higher for insurers with a generally lower insolvency probability. In our model, these are the insurers that have a high equity buffer, relatively mature insureds, 
472

and have written a large number of contracts. In addition, the underestimation risk is more severe for insurers heavily invested in stocks, both in absolute and relative terms.

Therefore, the interaction between mortality and macroeconomic conditions needs to be an integral part of life insurers' internal risk models, of capital allocation decision-making, and of solvency assessment by rating agencies and regulatory authorities. Taking this crucial relationship into consideration will make assessments of an insurer's risk situation more accurate and will thus more effectively protect policy-holders.

The results presented here are obtained within the specific dynamic asset liability model set out in Section "The simulation framework". Further research could incorporate alternative specifications for model assumptions such as the stochastic mortality model, the asset return process, the modelling of stochastic dependencies and the contract types within the life insurance portfolio held by the insurer. For example, applications of our model could involve investigating a more general insurance portfolio that includes a mixed age structure or annuity contracts. For a mixed age structure, we expect the following: As all age-specific mortality rates react in the same direction to changes in GDP, the resulting effect on insolvency probabilities would be a mixture of the age-specific increases shown in Figure 4. Including annuities, that is, contracts written on the opposite side of mortality risk, would give rise to natural hedging opportunities. ${ }^{33}$ In addition, dependencies between lapse and surrender rates and macroeconomic conditions could be accounted for. ${ }^{34}$ Finally, it should be a promising avenue of research to test empirically how much an insurer's solvency situation (e.g., with the rating as proxy) changes due to shocks to mortality. This could deliver important insights into the question whether investors or rating agencies are aware of the interaction between mortality and macroeconomic conditions and the resulting effect on insurers' solvency.

\section{Acknowledgements}

We are grateful for comments received from participants at the Annual Congress of the German Insurance Science Association (March 2009), at the $31^{\text {st }}$ U.K. Insurance Economists' Conference (March 2009), at the Annual Meeting of the American Risk and Insurance Association (August 2009), at the $36^{\text {th }}$ Seminar of the European Group of Risk and Insurance Economists (September 2009), and at the Longevity 5: The Fifth International Longevity Risk and Capital Markets Solutions Conference (September 2009). Furthermore, we would like to acknowledge the financial support from the German Research Foundation through the Collaborative Research Center 649 "Economic Risk".

\section{References}

Bauer, D. and Weber, F. (2008) 'Assessing investment and longevity risks within immediate annuities', Asia-Pacific Journal of Risk and Insurance 3(1): 89-111.

Booth, H. (2006) 'Demographic forecasting: 1980 to 2005 in review', International Journal of Forecasting 22(3): 547-581.

\footnotetext{
${ }^{33}$ See Gründl et al. (2006), Cox and Lin (2007), Tsai et al. (2010) and Wang et al. (2010).

${ }^{34}$ See Browne et al. (2001) and Kim (2005).
} 
Booth, H. and Tickle, L. (2008) 'Mortality modelling and forecasting: A review of methods', Annals of Actuarial Science 3(1-2): 3-43.

Booth, H., Maindonald, J. and Smith, L. (2002) 'Applying Lee-Carter under conditions of variable mortality decline', Population Studies 56(3): 325-336.

Booth, H., Hyndman, R.J., Tickle, L. and de Jong, P. (2006) 'Lee-Carter mortality forecasting: A multi-country comparison of variants and extensions', Demographic Research 15(9): 289-310.

Brouhns, N., Denuit, M. and Vermunt, J.K. (2002) 'A Poisson log-bilinear regression approach to the construction of projected lifetables', Insurance: Mathematics and Economics 31(3): 373-393.

Browne, M.J., Carson, J.M. and Hoyt, R.E. (2001) 'Dynamic financial models of life insurers', North American Actuarial Journal 5: 11-26.

Bureau of Economic Analysis (2008) 'National Economic Accounts, Gross Domestic Product', from www.bea.gov/national/index.htm\#gdp, accessed 30 April 2008.

Cairns, A.J.G., Blake, D. and Dowd, K. (2008) 'Modelling and management of mortality risk: A review', Scandinavian Actuarial Journal 2-3: 79-113.

Chow, G.C. (1960) 'Tests of equality between sets of coefficients in two linear regressions', Econometrica 28: 591-605.

Cox, S. and Lin, Y. (2007) 'Natural hedging of life and annuity mortality risks', North American Actuarial Journal 11(3): 1-15.

Debón, A., Montes, F. and Puig, F. (2008) 'Modelling and forecasting mortality in Spain', European Journal of Operational Research 189(3): 624-637.

Denuit, M.M. (2009) 'An index for longevity risk transfer', Journal of Computational and Applied Mathematics 230(2): 411-417.

Dowd, K., Cairns, A.J.G. and Blake, D. (2006) 'Mortality-dependent financial risk measures', Insurance: Mathematics and Economics 38(3): 427-440.

Ferro, G. (2009) 'One possible insurance market response to ageing', The Geneva Papers on Risk and Insurance-Issues and Practice 34(1): 119-136.

Gerdtham, U-G. and Ruhm, C.J. (2006) 'Deaths rise in good economic times: Evidence from the OECD', Economics \& Human Biology 4: 298-316.

Gründl, H., Post, T. and Schulze, R.N. (2006) 'To hedge or not to hedge: Managing demographic risk in life insurance companies', Journal of Risk and Insurance 73(1): 19-41.

Hanewald, K. (2010) 'Factors driving aggregate mortality rates in postwar Germany', Zeitschrift für die gesamte Versicherungswissenschaft 99: 211-229.

Hanewald, K. (2011) 'Explaining mortality dynamics: The role of macroeconomic fluctuations and cause of death trends', North American Actuarial Journal.

Hári, N., De Waegenaere, A., Melenberg, B. and Nijman, T.E. (2008a) 'Estimating the term structure of mortality', Insurance: Mathematics and Economics 42(2): 492-504.

Hári, N., De Waegenaere, A., Melenberg, B. and Nijman, T.E. (2008b) 'Longevity risk in portfolios of pension annuities', Insurance: Mathematics and Economics 42(2): 505-519.

Hyndman, R.J., Booth, H., Tickle, L. and Maindonald, J. (2008) 'Demography: Forecasting mortality and fertility data', R package, from http://robjhyndman.com, accessed 4 March 2009.

Kim, C. (2005) 'Modeling surrender and lapse rates with economic variables', North American Actuarial Journal 9(4): 56-70.

Kling, A., Richter, A. and Ruß, J. (2007) 'The interaction of guarantees, surplus distribution, and asset allocation in with-profit life insurance policies', Insurance: Mathematics and Economics 40(1): 164-179.

Kruse, S., Meitner, M. and Schröder, M. (2005) 'On the pricing of GDP-linked financial products', Applied Financial Economics 15(16): 1125-1133.

Lee, R.D. (2000) 'The Lee-Carter method for forecasting mortality, with various extensions and applications', North American Actuarial Journal 4: 80-93.

Lee, R.D. and Carter, L.R. (1992) 'Modeling and forecasting U.S. mortality', Journal of the American Statistical Association 87(419): 659-671.

Lee, R.D. and Miller, T. (2001) 'Evaluating the performance of the Lee-Carter method for forecasting mortality', Demography 38(4): 537-549.

Levy, R.I. (1981) 'Declining mortality in coronary heart disease', Arteriosclerosis, Thrombosis, and Vascular Biology 1: 312-325. 
Li, N., Lee, R.D. and Tuljapurkar, S. (2004) 'Using the Lee-Carter method to forecast mortality for populations with limited data', International Statistical Review 72(1): 19-36.

Mao, H., Ostaszewski, K.M. and Wang, Y. (2008) 'Risk analysis of mortality improvement: The case of Chinese annuity markets', The Geneva Papers on Risk and Insurance-Issues and Practice 33(2): 234-249.

McKay, M., Conover, W. and Beckman, R. (1979) 'A comparison of three methods for selecting values of input variables in the analysis of computer code', Technometrics 211: 239-245.

Morningstar (2008) Ibbotson SBBI 2008 Valuation Yearbook: Market Results for Stocks, Bonds, Bills, and Inflation, Chicago, IL: Morningstar Inc.

Neumayer, E. (2004) 'Recessions lower (some) mortality rates: Evidence from Germany', Social Science \& Medicine 58(6): 1037-1047.

Page, Y. (2001) 'A statistical model to compare road mortality in OECD countries', Accident Analysis and Prevention 33: 371-385.

Reichmuth, W.H. and Sarferaz, S. (2008) The influence of the business cycle on mortality, SFB 649 Discussion Paper 2008-059, Humboldt-Universität zu Berlin.

Renshaw, A.E. and Haberman, S. (2006) 'A cohort-based extension to the Lee-Carter model for mortality reduction factors', Insurance: Mathematics and Economics 38(3): 556-570.

Ruhm, C.J. (2000) 'Are recessions good for your health?' Quarterly Journal of Economics 115(2): 617-650.

Tapia Granados, J.A. (2005a) 'Increasing mortality during the expansion of the U.S. economy 1900-1996', International Journal of Epidemiology 34(6): 1194-1202.

Tapia Granados, J.A. (2005b) 'Recessions and mortality in Spain, 1980-1997', European Journal of Population 21(4): 393-422.

Tapia Granados, J.A. (2008) 'Macroeconomic fluctuations and mortality in postwar Japan', Demography 45(2): 323-343.

Tapia Granados, J.A. and Ionides, E.L. (2008) 'The reversal of the relation between economic growth and health progress: Sweden in the $19^{\text {th }}$ and $20^{\text {th }}$ centuries', Journal of Health Economics 27(3): 544-563.

Tuljapurkar, S., Li, N. and Boe, C. (2000) 'A universal pattern of mortality decline in the G7 countries', Nature 405: 789-792.

Tsai, J.T., Wang, J.L. and Tzeng, L.Y. (2010) 'On the optimal product mix in life insurance companies using conditional value at risk', Insurance: Mathematics and Economics 46(1): 235-241.

Uemura, K. and Pisa, Z. (1988) 'Trends in cardiovascular disease mortality in industrialized countries since 1950', World Health Statistics Quarterly 41(3-4): 155-178.

University of California, Berkeley (USA) and Max Planck Institute for Demographic Research (Germany) (2008) 'Human Mortality Database', from www.mortality.org, accessed 2 July 2008.

Wang, J.L., Huang, H.C., Yang, S.S. and Tsai, J.T. (2010) 'An optimal product mix for hedging longevity risk in life insurance companies: The immunization theory approach', Journal of Risk and Insurance 77(2): 473-497.

Yang, S.S. and Huang, H.C. (2009) 'The impact of longevity risk on the optimal contribution rate and asset allocation for defined contribution pension plans', The Geneva Papers on Risk and InsuranceIssues and Practice 34(4): 660-681.

\section{About the Authors}

Katja Hanewald is a Senior Research Associate at the School of Actuarial Studies at the University of New South Wales in Sydney. Her research interests include risk management and regulatory requirements for life insurers and pension funds, models to quantify risks related to longevity and morbidity, and individuals' perception of mortality and longevity risks.

Thomas Post is an Assistant Professor of Finance at Maastricht University and a member of Netspar. His research covers pension finance and household risk management, as well as corporate finance and risk management. 
Helmut Gründl holds the chair of Insurance and Regulation at the Goethe University in Frankfurt am Main and is managing director of the International Center for Insurance Regulation sponsored by the German Insurance Association (GDV) and the State of Hesse. Between 1999 and 2010, he held the chair for Insurance and Risk Management at Humboldt University of Berlin. His research interests cover all aspects of insurance regulation, risk management, insurance pricing and capital allocation. 